\title{
Bilateral Giant Mediastinal Parathyroid Adenomas Presented With Severe Hypercalcemia: Report of a Case
}

\author{
Baris Bayraktar ${ }^{\mathrm{a}}$, Gokhan Demiral ${ }^{\mathrm{b}, \mathrm{e}}$, Ibrahim Ali Ozemir ${ }^{\mathrm{a}}$, Onur Bayraktar ${ }^{\mathrm{c}}$, \\ Mehmet Gokce Yilmabasard, Salih Boluk ${ }^{\mathrm{a}}$
}

\begin{abstract}
Primary hyperparathyroidism (PHPT) is a common disorder of parathyroid gland and mostly results from parathyroid adenoma with the excess production of parathyroid hormone, usually causing hypercalcemia. This is the most common reason for surgical removal of parathyroid glands. It is mostly seen as single gland adenoma and bilaterality is very rare. In this study, we report a case of bilateral giant parathyroid adenomas represented with severe hypercalcemia, representing to our knowledge the largest masses to have been documented in the literature.
\end{abstract}

Keywords: Bilateral giant parathyroid adenomas; Hyperparathyroidism; Hypercalcemia

\section{Introduction}

Primary hyperparathyroidism (PHPT) is a condition characterized by the inappropriate secretion of parathyroid hormone $(\mathrm{PTH})$ with respect to the extracellular calcium concentration. It may result from the enlargement of a single gland or parathyroid adenoma in approximately $80 \%$ of cases, multiple adenomas or hyperplasia in $15-20 \%$ of patients and parathyroid carcinoma in $1 \%$ of patients [1]. PHPT occurs in a range 0.03 to $0.3 \%$ of the general population and

\footnotetext{
Manuscript accepted for publication January 6, 2014

${ }^{a}$ Department of General Surgery, Medeniyet University Goztepe Training and Research Hospital, Istanbul, Turkey

${ }^{\mathrm{b}}$ Department of General Surgery, Ardahan State Hospital, Ardahan, Turkey

${ }^{c}$ Department of General Surgery, Cerrahpasa Medical Faculty, Istanbul University, Istanbul, Turkey

${ }^{\mathrm{d}}$ Department of Radiology, Medeniyet University Goztepe Training and Research Hospital, Istanbul, Turkey

${ }^{\mathrm{e}}$ Corresponding author: Gokhan Demiral, Department of General

Surgery, Ardahan State Hospital, Ardahan, Turkey.

Email:drgokhandemiral@yahoo.com
}

doi: http://dx.doi.org/10.14740/jmc1686e is more common in women than in men (1:500 and 1:2,000) $[1,2]$.

Most patients with hyperfunctioning adenoma present with renal, skeletal, gastrointestinal and neuropsychiatric symptoms due to hypercalcemia [1]. Parathyroid adenomas are more frequently seen unilaterally and rarely determine in huge dimension bilaterally [3]. The treatment of adenomas is surgical excision, which should be curative if complete. The traditional surgical approach for parathyroidectomy is bilateral exploration of the neck via a collar incision, to examine all four glands and remove any diseased glands, with intra operative confirmation. However, based on the fact that most PHPT is caused by single gland disease, it is argued that a more limited surgical examination of the neck is also possible $[4,5]$.

\section{Case Report}

A 62-year-old man was referred to the Surgical Clinic of our Research and Training Hospital for evaluation of a raised serum calcium and parathyroid hormone level with symptoms of fatigue, unable to walk and lumbalgia. He was examined for the same symptoms 2 years ago and was found to have elevated blood urea nitrogen (BUN) $(71 \mathrm{mg} / \mathrm{dL}$, normal range $5-23 \mathrm{mg} / \mathrm{dL})$ and creatinin $(1.3 \mathrm{mg} / \mathrm{dL}$, normal range 0.6 - $1.2 \mathrm{mg} / \mathrm{dL}$ ) levels and after determining parathyroid adenoma, he refused to undergo parathyroidectomy.

In his last course, the biochemical investigation confirmed significant hypercalcemia $(19.24 \mathrm{mg} / \mathrm{dL}$; the normal range $8.5-10.5 \mathrm{mg} / \mathrm{dL}$ ) with an elevated PTH level of 3,436 $\mathrm{pg} / \mathrm{mL}$ (reference rates $15-65 \mathrm{pg} / \mathrm{mL}$ ) and signs of chronic renal failure (BUN $181 \mathrm{mg} / \mathrm{dL}$ and creatinin $2.2 \mathrm{mg} / \mathrm{dL}$ ). However, he was found to have subclinic hyperthyroidism with thyroid stimulating hormone and free thyroxine (fT4) levels of $0.14 \mu \mathrm{U} / \mathrm{mL}$ (reference $0.5-5 \mu \mathrm{U} / \mathrm{mL}$ ) and $1.13 \mathrm{ng} /$ $\mathrm{dL}$ (reference 0.8 - $2 \mathrm{ng} / \mathrm{dL}$ ) respectively.

Tc-99m sestamibi scintigraphy (MIBI), the differential diagnostic modality for parathyroid adenomas, showed no significant findings (Fig. 1). Neck ultrasonography showed bilateral posterior mediastinal masses with a concomitant multinodular goiter (suspect hypoechoic nodules). Follow- 


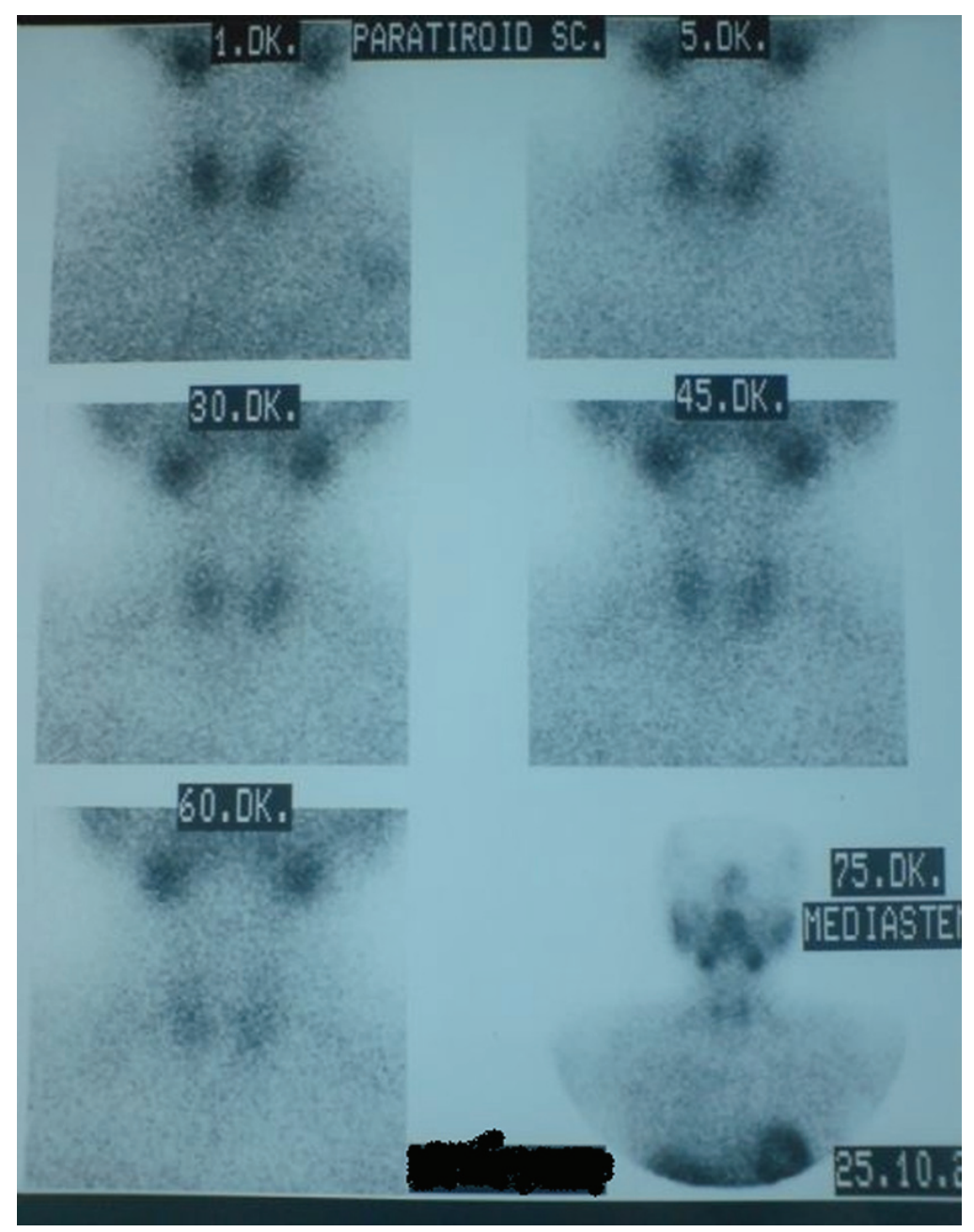

Figure 1. Tc-99m sestamibi scintigraphy of the patient that was reported as normal parathyroid gland.

ing neck magnetic resonance imaging (MRI) was useful for diagnosis and localizing the adenomas (Fig. 2).

Preoperative calcium level was decreased to $10.25 \mathrm{mg} /$ $\mathrm{dL}$ level with forced diuresis after 13 days follow-up period.

Following a Coller insicion, the thyroid gland and all parathyroid glands were explorated. We diagnosed multinodular goiter and bilateral inferior huge parathyroid glands with enlarged right superior parathyroid gland. Thus, we performed bilateral total tyroidectomy + right superior and bilateral inferior parathyroidectomy. Right inferior parathyroid gland was measuring $5.5 \times 4.5 \times 3.5 \mathrm{~cm}$, weighing $74 \mathrm{~g}$ (Fig. 3 ) and left inferior parathyroid gland was measuring 6 $\times 4.5 \times 3 \mathrm{~cm}$, weighing $102 \mathrm{~g}$ (Fig. 4). Right superior parathyroid gland was measuring $2 \times 1 \times 1 \mathrm{~cm}$, weighing $100 \mathrm{mg}$. Postoperatively, serum calcium and PTH levels returned to normal levels (serum calcium level $9.55 \mathrm{mmol} / \mathrm{L}$ and PTH level $70 \mathrm{pg} / \mathrm{mL}$ ).

The patient has hoarseness after the operation and his voice returned to normalcy on postoperative third month.
The specimens were reported histopathologically as bilateral parathyroid adenomas and bilateral adenomatous hyperplasia of thyroid. The right superior parathyroid gland was histologically reported as normal parathyroid specimen. After 12 months of follow-up, the patient remains disease free.

\section{Discussion}

Hyperfunction of the parathyroid glands may be classified as primary, secondary or tertiary. PHPT arises from increased PTH production from abnormal parathyroid glands and results from a disturbance of normal feedback control mechanism exerted by serum calcium [1]. Increased PTH production leads to hypercalcemia via increased gastrointestinal absorbtion of calcium, increased production of vitamin D3 and reduced renal calcium clearence [1]. PHPT is the most common cause of hypercalcemia in unselected patients. 


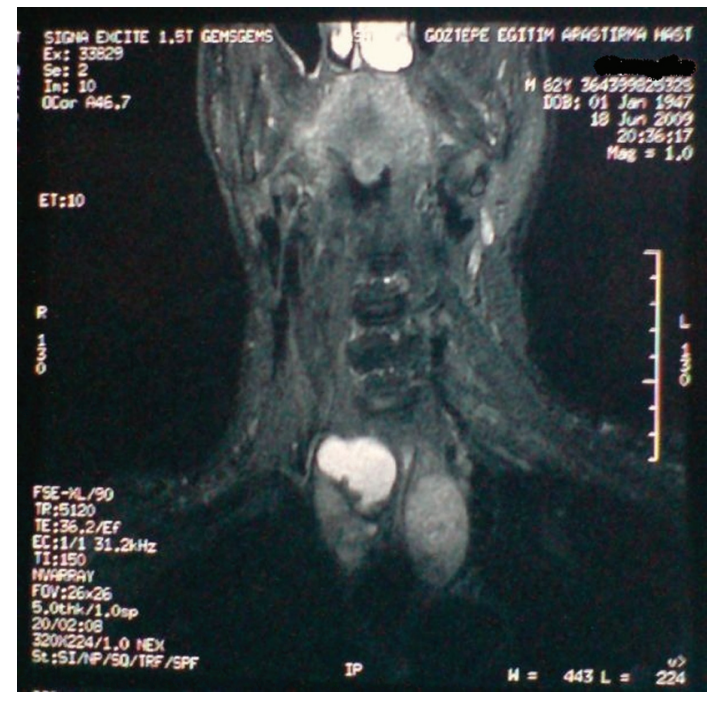

Figure 2. Neck MRI showed bilateral giant parathyroid adenomas.

Although parathyroid disease is relatively uncommon, $80 \%$ of all cases of PHPT are caused by a single adenoma $[1,3,6]$, while multiple gland hyperplasia occurs in $12-15 \%$, double adenoma in $2-3 \%$ and carcinoma in about $1 \%[1,7]$.

Patients with PHPT formerly presented with the classic pentad of symptoms (kidney stones, painful bones, abdominal groans, psychic moans and fatigue overtones). With the advent and widespread use of automated blood analyzers in early 1970s, there has been an alteration in the typical patient with PHPT, who is more likely to be minimally symptomatic or asymptomatic. Currently, most patients present with weakness, fatigue, hypertension, polydipsia, polyuria, nocturia, bone and joint pain, constipation, decreased appetite, nausea, heartburn, pruritus, depression and memory loss. Furthermore, these symptoms and signs improve in most, but certainly not at all, patients after parathyroidectomy [1, 8]. In our patient chronic renal failure and osteoporosis were the main findings.

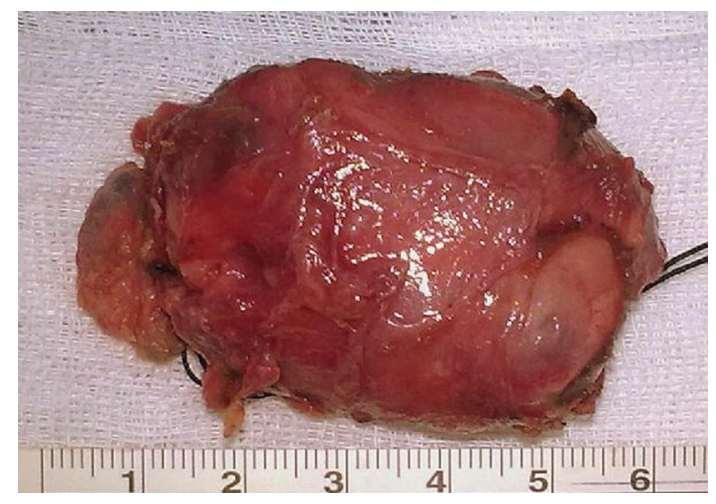

Figure 3. Right inferior parathyroid gland of the patient.

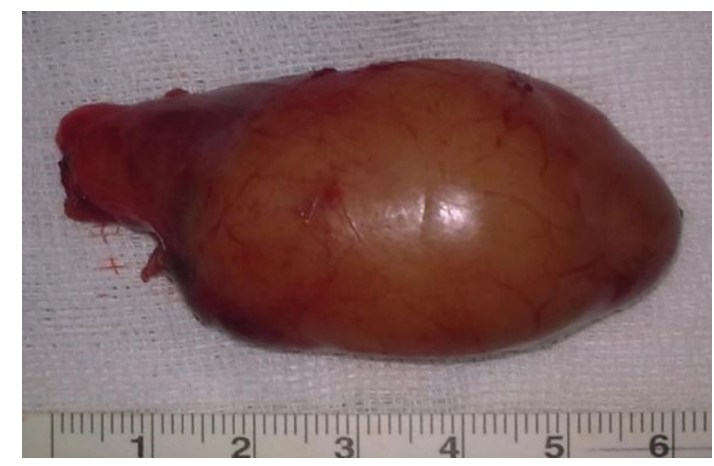

Figure 4. Left inferior parathyroid gland of the patient.

Although PTH secretion is modulated by serum calcium level, many studies have established a direct relationship between gland weight and serum PTH and calcium levels. Similarly, it has been found that an increased glandular mass correlates with the severity of PHPT and the subsequent risk of transient postoperative hypocalcemia [6]. Our patient had bilateral giant adenoma and significant preoperative hypercalcemia $(19.24 \mathrm{mg} / \mathrm{dL})$, but postoperative calcium levels were within normal ranges.

Normally, there are two pairs of parathyroid glands in adult humans. Each gland is usually $3 \times 4 \times 5 \mathrm{~mm}$ in size and weighs between 30 and $50 \mathrm{mg}$. A single gland weight above $60 \mathrm{mg}$ is abnormal [3]. The usual weight of a parathyroid adenoma ranges from $70 \mathrm{mg}$ to $1 \mathrm{~g}$, although there are sporadic reports of tumors weighing more than $20 \mathrm{~g}$. Bilateral giant paratyhroid adenomas are extremely rare [6]. There are sporadic reports of large adenomas attaining masses of $70 \mathrm{~g}$. At surgery we identified concomittant goitre and bilateral giant paratyhroid adenomas, extending into the posterior mediastinum and weighed $74 \mathrm{~g}$ right side and $102 \mathrm{~g}$ left side.

Although parathyroid localization is essential in cases requiring reexploration, there is considerable controversy regarding the indications for localization studies prior to primary exploration, since the success rate for surgery exceeds $90 \%$ to $95 \%$. However, in specific circumstances including diagnostic problems, technical considerations and high risk patient factors, preoperative parathyroid localization assists the operating surgeon even during the primary cervical exploration [9].

Proponents of localization studies advocate their use to decrease operative time and potential morbidity. This idea often allows for a unilateral neck exploration to decrease the risk of hypocalcemia and recurrent laryngeal nerve injury [10].

Parathyroid scintigraphy is a modality for localization, but not diagnosis, of the parathyroid adenomas. Tc-99mlabeled sestamibi scintigraphy is the most widely used and accurate modality with sensitivity greater than $80 \%$ for localization of paratyhroid adenomas [1]. But in our patient Tc-99m-sestamibi scintigrapy was reported normally. 
Sestamibi scans are generally complemented by neck ultrasound which can identify adenomas with greater than $75 \%$ sensivity in experienced centers and is most useful in identifying intrathyroidal parathyroids $[1,3]$. CT and MRI scans are less sensitive than sestamibi scans, but are helpful in localizing mediastinal glands [1]. In our case neck ultrasonography showed bilateral posterior mediastinal masses with a concomitant multinodular goiter.

Neck MRI and CT were also useful for diagnosis and localizing the adenomas whenever neck ultrasonography indicates bilateral posterior mediastinal masses.

Advances in surgery have popularized the minimally invasive procedure under local anesthesia. It requires successful preoperative localization of the abnormal parathyroid gland and capability to measure PTH rapidly in the operating room [11]. A preoperative blood sample is obtained for comparison of the PTH concentration with an intraoperative sample obtained minutes after removal of the abnormal parathyroid gland. If the PTH level falls by more than $50 \%$ immediately following resection, the gland that has been removed is considered to be the sole source of overactive parathyroid tissue and the operation is terminated. If the PTH level does not fall by more than $50 \%$, the operation is extended to a more traditional one in a search for other overactive parathyroid tissue. This aproach helps the operating surgeon especially in small adenomas and parathyroid hyperplasias. Because of the diagnosis of adenoma preoperatively, we did not need to measure PTH intraoperatively in our patient. With advances in imaging technology and growing experience with minimally invasive parathyroid surgery, it is likely that these newer approaches will become more widely used [12].

Long-term follow-up of these patients indicates a 10$12 \%$ improvement in bone density at the lumbar spine and femoral neck over 10 years $[13,14]$. In patients who have nephrolithiasis, surgery is of clear benefit in reducing the incidence of recurrent stones [15]. Vague or constitutional symptoms may or may not improve after surgery, while hypertension and peptic ulcer disease if present, are unlikely to remit.

Successful surgery supported with medical therapy cures PHPT and improves most of the symptoms associated with hypercalcemia.

\section{References}

1. Brunicardi FC, Andersen DK, Billiar TR, Dunn DL, Hunter JG, Poilock RE. Schwartz' s manual of surgery, 8th ed. New york: McGraw Hill; 2006. p.962-974.

2. Bilezikian JP, Silverberg SJ. Clinical spectrum of primary hyperparathyroidism. Rev Endocr Metab Disord. 2000;1(4):237-245.

3. Lee NC, Norton JA. Multiple-gland disease in primary hyperparathyroidism: a function of operative approach? Arch Surg. 2002;137(8):896-899; discussion 899-900.

4. Palazzo FF, Sadler GP. Minimally invasive parathyroidectomy. BMJ. 2004;328(7444):849-850.

5. Johnson SJ, Sheffield EA, McNicol AM. Best practice no 183. Examination of parathyroid gland specimens. J Clin Pathol. 2005;58(4):338-342.

6. Power C, Kavanagh D, Hill AD, O'Higgins N, McDermott E. Unusual presentation of a giant parathyroid adenoma: report of a case. Surg Today. 2005;35(3):235-237.

7. Summers GW. Parathyroid update: a review of 220 cases. Ear Nose Throat J. 1996;75(7):434-439.

8. Sathe PA, Madiwale CV, Kandalkar BM, Bandgar TR, Shah NS, Menon PS. Primary hyperparathyroidism: a clinicopathological experience. Indian J Pathol Microbiol. 2009;52(3):313-320.

9. Shaha AR, LaRosa CA, Jaffe BM. Parathyroid localization prior to primary exploration. Am J Surg. 1993;166(3):289-293.

10. Roe SM, Burns RP, Graham LD, Brock WB, Russell WL. Cost-effectiveness of preoperative localization studies in primary hyperparathyroid disease. Ann Surg. 1994;219(5):582-586.

11. Clark $\mathrm{OH}$. How should patients with primary hyperparathyroidism be treated? J Clin Endocrinol Metab. 2003;88(7):3011-3014.

12. Udelsman R, Donovan PI, Sokoll LJ. One hundred consecutive minimally invasive parathyroid explorations. Ann Surg. 2000;232(3):331-339.

13. Grey A, Lucas J, Horne A, Gamble G, Davidson JS, Reid IR. Vitamin D repletion in patients with primary hyperparathyroidism and coexistent vitamin D insufficiency. J Clin Endocrinol Metab. 2005;90(4):2122-2126.

14. Gallagher SF, Denham DW, Murr MM, Norman JG. The impact of minimally invasive parathyroidectomy on the way endocrinologists treat primary hyperparathyroidism. Surgery. 2003;134(6):910-917; discussion 917.

15. Nomura R, Sugimoto T, Tsukamoto T, Yamauchi M, Sowa H, Chen Q, Yamaguchi T, et al. Marked and sustained increase in bone mineral density after parathyroidectomy in patients with primary hyperparathyroidism; a six-year longitudinal study with or without parathyroidectomy in a Japanese population. Clin Endocrinol (Oxf). 2004;60(3):335-342. 